\title{
Survival of sealants in molars affected by molar-incisor hypomineralization: 18-month follow-up
}

\section{Camila Maria Bullio FRAGELLI ${ }^{(a)}$ Juliana Feltrin de SOUZA ${ }^{(b)}$ \\ Diego Girotto BUSSANELI ${ }^{(a)}$ \\ Fabiano JEREMIAS(a) \\ Lourdes dos SANTOS-PINTO(a) Rita de Cássia Loiola CORDEIRO(a)}

(a) Universidade do Estado de São

Paulo - Unesp, Araraquara Dental School, Department of Orthodontics and Pediatric Dentistry, Araraquara, São Paulo, Brazil.

(b) Universidade Federal do Paraná - UFPR, School of Dentistry, Department of Stomatology, Curitiba, Paraná, Brazil.

Declaration of Interest: The authors certify that they have no commercial or associative interest that represents a conflict of interest in connection with the manuscript.

Corresponding Author: Juliana Feltrin de Souza

E-mail: julianafeltrin1@gmail.com

https://doi.org/10.1590/1807-3107BOR-2017.vol31.0030

Submitted: July 06, 2016

Accepted for publication: March 06, 2017

Last revision: March 16, 2017
Abstract: The objective of this study was to evaluate the clinical survival of sealants applied in first permanent molars (FPMs) affected by molar-incisor hypomineralization $(\mathrm{MIH})$, at 18 months of follow-up. Forty-one first permanent molars were selected from 21 children, 6-8 years of age. $\mathrm{MIH}$ was classified by one calibrated examiner (kappa $=0.80)$ according to EAPD criteria. The inclusion criteria were fully erupted FPMs with MIH or sound FPMs (without MIH) for which sealant treatment was indicated. The FPMs were assigned to two groups: CG (control group) and HG (MIH group). Both groups were treated with sealant (FluroShield). Clinical follow-up was performed from baseline to 18 months to assess anatomical form, marginal adaptation, retention and presence of caries, according to criteria set by the United States Public Health Service-Modified, and was conducted by a blinded examiner (kappa $=0.80)$. The actuarial method was used to evaluate the survival of the sealants. The survival rates for the groups were compared using Fisher's exact test $(\alpha=5 \%)$. The cumulative survival rates were $81 \%$ at 1 month, $68.8 \%$ at 6 months, $68.8 \%$ at 12 months, and $62.6 \%$ at 18 months for CG, and $88 \%$ at 1 month, $84 \%$ at 6 months, $76 \%$ at 12 months, and $72 \%$ at 18 months for HG. No significant difference was found between the groups. The sealants in molars affected by $\mathrm{MIH}$ presented a survival rate similar to the sealants in the control, suggesting that sealants may be an adequate approach for preventing carious lesions in MIH-affected molars.

Keywords: Molar Incisor Hypominerazation; Pit and Fissure Sealants; Preventive Dentistry; Survival Rates.

\section{Introduction}

Molar-incisor hypomineralization (MIH) is a congenital alteration of tooth enamel that affects one or more first permanent molars (FPMs) and often permanent incisors, with varying degrees of severity. ${ }^{1,2,3}$ The affected enamel presents demarcated opacities of different colors, which occasionally undergo post-eruptive breakdown because of enamel porosity, ${ }^{4}$ leading to results ranging from mild aty pical cavities to severe coronary destruction ${ }^{4,5,6}$ that may require a more in-depth $\mathrm{MIH}$ diagnosis and preventive treatment with fluoride and sealants in patients affected by MIH. ${ }^{6,7}$ The studies have suggested that FPMs affected by MIH are more susceptible to dental caries than non-affected 
teeth, mainly because of the lower resistance to caries lesion and enamel fracture, which can lead to enamel breakdown. $6,8,9,10,11$

Another fundamental aspect is related to chronic inflammation of FPM pulp affected by MIH. This inflammation is responsible for heightened sensitivity and is directly related to greater innervation of the region under the hypomineralized area. ${ }^{12}$ This inflammation may also make it difficult to clean MIH-affected FPMs, contributing to the development of carious lesions. Therefore, patients with MIH should be viewed as having a high risk of caries, requiring preventive treatment as soon as FPMs erupt in their mouth. $6,7,13$

The available treatment modalities for MIH-affected FPMs are extensive, including prevention, restoration and even extraction. ${ }^{7}$ Fissure sealants may be useful to treat FPMs with mild MIH before breakdown occurs, especially when teeth are fully erupted and when moisture control is adequate.,14 Moreover, this type of treatment is particularly suitable when the sealants are regularly monitored, and may be replaced when they fail. ${ }^{15,16,17}$ However, evidence of the retention and longevity of these sealants for treating MIH-affected FPMs is limited. Kotsanos et al. ${ }^{17}$ performed a retrospective analysis and found that fillings and sealants in MIH-affected children had a greater probability of requiring retreatment, compared with the control group. Lygidakis et al. ${ }^{18}$ concluded that hypomineralized molars with occlusal opacities seem to have greater retention when $5^{\text {th }}$-generation adhesive systems are applied prior to the sealant. However, the present study was not a prospective study.

$\mathrm{MIH}$ is prevalent in the population. ${ }^{19}$ Considering that $\mathrm{MIH}$-affected FPMs may require more restorative and preventive treatment, studies evaluating the survival rate of these treatments are important for clinical practice. Only scant information is available in the literature about the survival of sealants in hypomineralized enamel. Thus, the aim of the present study was to assess sealant survival in FPMs affected by MIH, and compare the survival rate with sealants applied to sound molars at 18 months of follow-up.

\section{Methodology}

This study was conducted according to the Helsinki Declaration. Approval was obtained from the Ethics and Research Committee of the Araraquara Dental School, São Paulo, Brazil (protocol no. 11/09). All of the children's parents/guardians signed an informed consent form.

\section{Study design}

The present prospective clinical study performed preventive treatment with sealants in two groups: FPMs affected by MIH (HG group) and FPMs unaffected by MIH (CG group) but having enamel caries lesion or high dental caries risk. The indication for the sealant was evaluated according to the caries risk assessment of the patient and tooth morphology. The sealants were followed up for 18 months.

\section{Subjects}

A previous epidemiological study ${ }^{9}$ evaluated 1147 children, aged 6-12 years. Of these, 142 were diagnosed with MIH according to the European Academy of Paediatric Dentistry (EAPD) criteria, and found to have a total of 231 first permanent molars needing preventive care. ${ }^{20}$ The parents/guardians of these children were invited to participate in the present study (Figure 1), and those of 29 children who met the inclusion criteria agreed to participate in the study. Of these 29 children, 21 were followed up for 18 months. Although the sample in the present study was selected from a population-based study, the sample size of 77 molars per group was deemed adequate for detecting significant differences between the groups, considering the probability of the event (failure) and a hazard ratio at a level of significance of 0.05 and power of $0.80 .{ }^{21}$

The inclusion criteria were 6- to 8-year-old children born and living in Araraquara, São Paulo, Brazil, and presenting FPMs that were affected or unaffected by $\mathrm{MIH}$, that were fully erupted, and that had enamel caries lesion or were at risk for carious lesions.

The authors selected FPMs presenting occlusal surfaces with sound pits and fissures, which had enamel lesion caries or were at risk for carious lesions, and for which sealant treatment was indicated. The HG group included FPMs with MIH of mild severity that 
presented white, yellow, and brown opacities, and that showed both mechanical and chemical alteration of the enamel, ${ }^{4}$ consequently being at a high risk for carious lesion or breakdown. $6,7,9$

The exclusion criteria for both groups included FPMs with cavitated carious lesions or fixed orthodontic appliances, FPMs classified as having severe $\mathrm{MIH}$, presenting enamel breakdown, or FPMs with other enamel malformations linked to specific syndromes and/or dental fluorosis. After subject selection, a total of 41 FPMs were included (16 unaffected by MIH and 25 affected by MIH).

\section{Calibration of the examiner for the evaluations}

The examiner was calibrated for MIH, based on criteria set by the EAPD ${ }^{20}$ and the United States Public Health Service (USPHS)-Modified. ${ }^{22}$ The examiner previously assessed 32 clinical photographs of patients from the Pediatric Dentistry Clinic of the Araraquara Dental School, São Paulo, Brazil, and then participated in a discussion on all the indices and codes, with the $\mathrm{MIH}$ research team. After the parties reached an agreement, 30 patients with enamel alterations ( 17 with $\mathrm{MIH})$ were evaluated. After 2 weeks, the patients were reevaluated, and the kappa coefficient was applied to verify agreement between the evaluations. The intraexaminer kappa coefficients for MIH and USPHS-Modified were 0.80 and 0.85 , respectively.

\section{Treatment}

The 41 FMPs were clinically examined and classified according to the presence of $\mathrm{MIH}$, based on the EAPD (2003), and then divided into two groups by a calibrated examiner: $\mathrm{CG}$ (teeth unaffected by $\mathrm{MIH}$ ) and HG (teeth affected by MIH). Another operator with 10 years of clinical experience performed the preventive procedures at the Periodontics Clinic of São

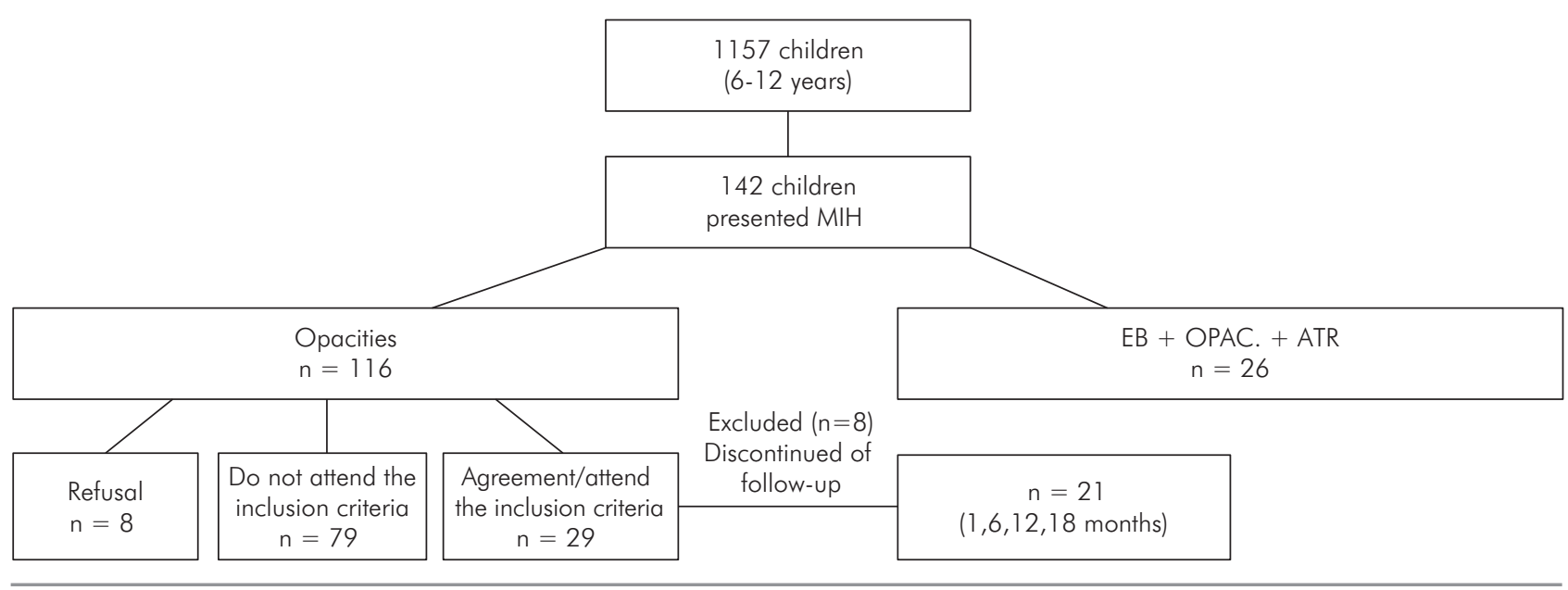

Figure 1. Number of subjects of the study. OPAC, opacities; EB, enamel breakdown; ATR, atypical restoration.

Table 1. Composition of materials used in the present study.

\begin{tabular}{|c|c|c|c|}
\hline Product name & Manufacturer & Composition & Usage instructions \\
\hline FluroShield & Dentsply /Caulk, Milford, DE, USA & $\begin{array}{l}\text { Urethane Bis-GMA; Dimethacrylate } \\
\text { resins; Barium aluminoborosilicate } \\
\text { glass; Sodium Fluoride; Photoinitiator; } \\
\text { Photoaccelerators; Silicon Dioxide. }\end{array}$ & $\begin{array}{l}\text { Apply sealant material along length of } \\
\text { fissure. Light cure all coated surfaces, } \\
\text { keeping end of light tip about 1-2mm } \\
\text { from the surface. }\end{array}$ \\
\hline Duraphat & Colgate/Palmolive, New York, NY, USA & $\begin{array}{c}1 \mathrm{~mL} \text { of this suspension contains } 50 \mathrm{mg} \\
\text { sodium fluoride, equivalent to } 22.6 \mathrm{mg} \\
\text { fluoride, in an alcoholic solution of } \\
\text { natural resins. }\end{array}$ & $\begin{array}{l}\text { Duraphat }{ }^{\circledR} \text { fluoride varnish can be } \\
\text { applied with cotton swabs, a brush or } \\
\text { a probe. It is recommended that the } \\
\text { patient not eat hard foods or brush for } \\
\text { at least two hours after the application. }\end{array}$ \\
\hline
\end{tabular}


Paulo State University. The materials, compositions and manufacturer's instructions are shown in Table 1.

Both the CG and HG groups underwent a standard protocol for sealant treatment. The FPMs initially received pretreatment with four weekly applications of fluoride varnish (Duraphat, Colgate-Palmolive, New York, USA) using an applicator (Microblush, Crafton, USA) with cotton roll isolation at 1 -week intervals. ${ }^{23}$

The sealant treatment was conducted according to the following clinical steps: prophylaxis, infiltrative anesthesia, rubber dam, application of 35\% phosphoric acid (Scotchbond etchant, 3M/ESPE, St. Paul, USA) for $30 \mathrm{~s}$, extensive rinsing drying and air jet for $5 \mathrm{~s}$, resin sealant application (Fluroshield, Dentsply/Caulk, Milford, DE, USA), light curing for $20 \mathrm{~s}$ (Elipar Freelight 2, 3M ESPE, St. Paul, MN, USA), removal of rubber dam, examination of occlusal contact and final polishing.

\section{Follow-up and clinical evaluation}

The four clinical exams at 1, 6, 12 and 18 months were performed in a clinical environment, as established by the World Health Organization, ${ }^{24}$ under artificial light and after prophylaxis. The sealants were clinically evaluated by a calibrated examiner $(\mathrm{kappa}=0.80)$ according to the USPHS-Modified, ${ }^{22}$ which considers the aspects of anatomical form, marginal adaptation, surface texture, marginal discoloration, retention and presence of secondary carious lesions. The sealants were also classified as satisfactory (for Alpha and Bravo scores) or unsatisfactory (for the Charlie score). When the sealant received a Charlie rating based on the USPHS-Modified criteria (Table 2), the sealant was deemed unsatisfactory. ${ }^{25}$ Sealants classified as unsatisfactory were considered a failure, and the treatment was replaced and no longer considered for evaluation in the present study.

\section{Statistical analysis}

The data were analyzed using SPSS 16.0 software (Chicago, USA). Association between the independent variable (group) and the dependent variable (clinical evaluation score) were assessed using Fisher's exact test at a $5 \%$ level of significance. The actuarial method and survival curves were used to evaluate the survival of the sealants.

\section{Results}

A total of 41 FPMs in 21 children were followed. The mean age was 7 years old (range of 6-8 years), and $52.3 \%$ of the sample was male. Table 3 shows the

Table 2. United States Public Health Service-Modified classification of teeth as satisfactory or unsatisfactory.

\begin{tabular}{|c|c|c|}
\hline \multirow{3}{*}{ Anatomic form } & Alfa & Continuous \\
\hline & Bravo & Slight discontinuity, clinically acceptable \\
\hline & Charlie & Discontinuous, failure \\
\hline \multirow{3}{*}{ Marginal adaptation } & Alfa & Closely adapted, no visible crevice \\
\hline & Bravo & Visible crevice, explorer will penetrate \\
\hline & Charlie & Crevice in which dentin is exposed \\
\hline \multirow{3}{*}{ Surface texture } & Alfa & Enamel-like surface \\
\hline & Bravo & Surface rougher than enamel, clinically acceptable \\
\hline & Charlie & Surface unacceptably rough \\
\hline \multirow{3}{*}{ Marginal discoloration } & Alfa & No discoloration \\
\hline & Bravo & Discoloration without penetration in pulpal direction \\
\hline & Charlie & Discoloration with penetration in pulpal direction \\
\hline \multirow{2}{*}{ Retention } & Alfa & No loss of restorative material \\
\hline & Charlie & Loss of restorative material \\
\hline \multirow{2}{*}{ Secondary saries } & Alfa & No caries present \\
\hline & Charlie & Caries present \\
\hline
\end{tabular}


sealant failure frequencies, with six breakdowns in 1 month, one breakdown in 6 months, four breakdowns in 12 months, and two breakdowns in 18 months. The breakdowns occurred with six sealants in the CG group and seven sealants in the HG group (Table 3). Breakdowns occurred in three teeth with yellow opacity and four teeth with brown opacity (Figure 2). The percentages of sealants that remained unchanged at 18 months were $62 \%$ for the CG group and $72 \%$ for the HG group (Table 3, Figure 3), thus not representing significantly different results.

The teeth that presented more failures were numbers 16 and 26 in both groups (Figure 4). Two teeth presented caries associated with sealant failure, both occurring in the HG group (Table 4). No significant differences between 1, 6, 12 and 18 months of follow-up were observed for any of the assessment criteria (Table 4).

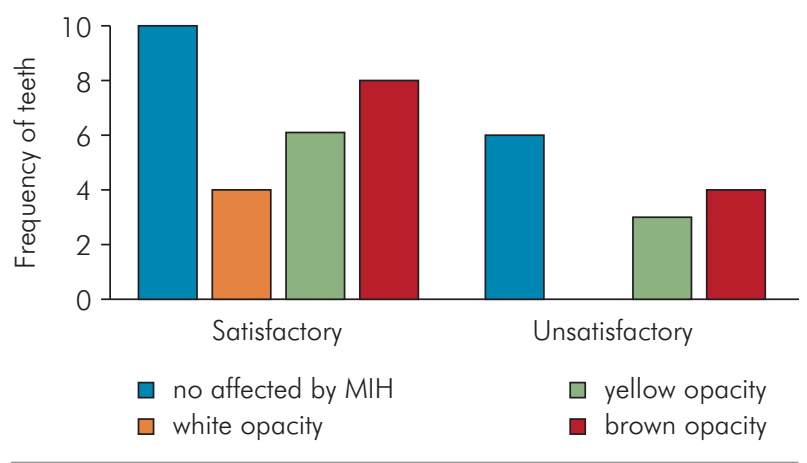

Figure 2. Frequency of satisfactory and unsatisfactory sealants according to $\mathrm{MlH}$ severity

\section{Discussion}

FPMs affected by MIH require preventive care, because there is a high risk of post-eruptive fractures that result from masticatory forces and acidogenic challenges of the oral cavity. ${ }^{6,26}$ Once the fracture occurs, the subsurface enamel and/or dentin is exposed, resulting in sensitivity to cold, heat and brushing, and

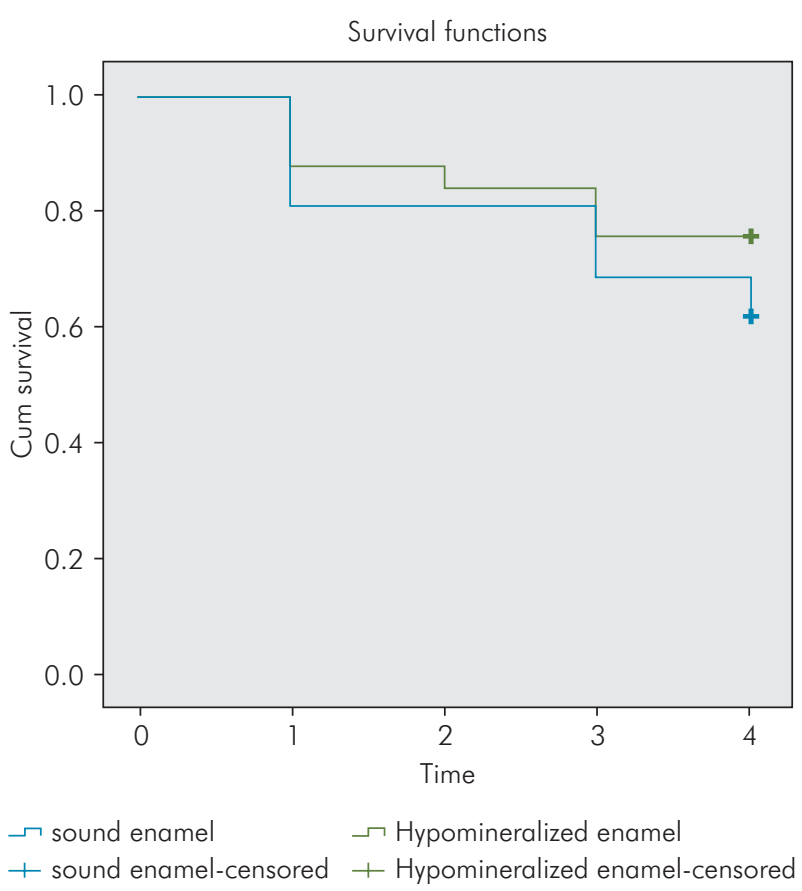

Figure 3. Sealant survival over time (Kaplan-Meier test). Where: Censored data was attributed to satisfactory restoration at the 18th month

Table 3. Actuarial method for survival analysis of CG (control group) and HG (affected group) at 1, 6, 12 and 18 months of follow-up.

\begin{tabular}{|c|c|c|c|c|c|c|}
\hline Variable & Interval (months) & $\begin{array}{l}\text { Subjects living at } \\
\text { start of interval }\end{array}$ & $\begin{array}{l}\text { Deaths during } \\
\text { the interval }\end{array}$ & $\begin{array}{l}\text { Death rate during } \\
\text { the interval }\end{array}$ & $\begin{array}{l}\text { Survival rate during } \\
\text { the interval }\end{array}$ & $\begin{array}{l}\text { Cumulative survival } \\
\text { rate to end of interval }\end{array}$ \\
\hline \multirow{4}{*}{$\begin{array}{l}\text { Control } \\
\text { group }\end{array}$} & $0-1$ & 16 & 3 & 0.187 & 0.813 & 0.813 \\
\hline & $1-6$ & 13 & 0 & 0.000 & 1.000 & 0.813 \\
\hline & $6-12$ & 13 & 2 & 0.153 & 0.847 & 0.688 \\
\hline & 12-18 & 11 & 1 & 0.090 & 0.910 & 0.626 \\
\hline \multirow{4}{*}{$\begin{array}{l}\text { Affected } \\
\text { group }\end{array}$} & $0-1$ & 25 & 3 & 0.120 & 0.880 & 0.880 \\
\hline & $1-6$ & 22 & 1 & 0.045 & 0.955 & 0.840 \\
\hline & $6-12$ & 21 & 2 & 0.095 & 0.905 & 0.760 \\
\hline & $12-18$ & 19 & 1 & 0.052 & 0.948 & 0.720 \\
\hline
\end{tabular}

Differences between the groups were analyzed by the Log Rank Mantel-Cox test $(p>0.05)$. 
possibly leading to further accumulation of plaque and development of caries. ${ }^{17,27}$ Sealant treatment for $\mathrm{MIH}$ may be an effective alternative to preventing caries.

A 9-year follow-up study found that sealants decreased the incidence of occlusal caries by $65.4 \%$,

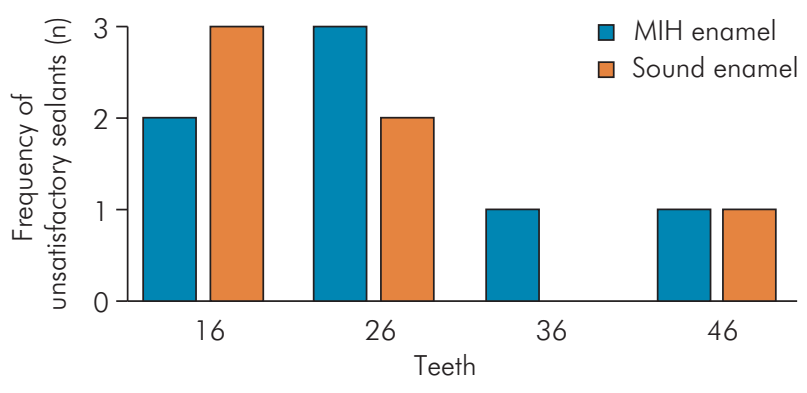

Figure 4. Frequency of unsatisfactory sealants according to the type of tooth in each group after 18 months of follow-up. compared with the control group. ${ }^{28}$ During the follow-up period of the present study, 13 sealant failures were observed, and only 2 were associated with caries, both occurring in the MIH-affected group (HG). These findings agree with those of previous studies, highlighting the greater risk of developing carious lesions in patients with $\mathrm{MIH}$. ${ }^{8,10,11,}$

Adhesion is a key factor for the success of sealants when considering hypomineralized enamel that undergoes chemical, mechanical and morphological alterations. ${ }^{4}$ These alterations may negatively influence the retention and longevity of the sealant, thus compromising the preventive action of the sealant. The literature on adhesion in hypomineralized enamel is still limited, ${ }^{25,29}$ especially in regard to the use of sealants.

Table 4. Criteria for satisfactory and unsatisfactory sealants for CG (control group) and HG (affected group) at 1, 6, 12 and 18 months of follow-up.

\begin{tabular}{|c|c|c|c|c|c|c|c|c|}
\hline \multirow{2}{*}{ Criteria } & \multicolumn{2}{|c|}{1 Months } & \multicolumn{2}{|c|}{6 Months } & \multicolumn{2}{|c|}{12 Months } & \multicolumn{2}{|c|}{18 Months } \\
\hline & CG & $H G$ & CG & $H G$ & CG & $H G$ & CG & $\mathrm{HG}$ \\
\hline \multicolumn{9}{|l|}{ Anatomic form } \\
\hline Satisfactory & 16 & 25 & 13 & 22 & 12 & 20 & 10 & 19 \\
\hline Unsatisfactory & 0 & 0 & 0 & 0 & 1 & 1 & 1 & 0 \\
\hline$p$ & \multicolumn{2}{|c|}{$p=1.000^{*}$} & \multicolumn{2}{|c|}{$p=1.000^{*}$} & \multicolumn{2}{|c|}{$p=1.000^{*}$} & \multicolumn{2}{|c|}{$p=0.366^{*}$} \\
\hline \multicolumn{9}{|c|}{ Marginal adaptation } \\
\hline Satisfactory & 15 & 24 & 13 & 22 & 12 & 19 & 10 & 19 \\
\hline Unsatisfactory & 1 & 1 & 0 & 0 & 1 & 2 & 1 & 0 \\
\hline$p$ & \multicolumn{2}{|c|}{$p=1.000^{*}$} & \multicolumn{2}{|c|}{$p=1.000^{*}$} & \multicolumn{2}{|c|}{$p=1.000^{*}$} & \multicolumn{2}{|c|}{$p=0.366^{*}$} \\
\hline \multicolumn{9}{|l|}{ Surface texture } \\
\hline Satisfactory & 15 & 25 & 12 & 22 & 12 & 20 & 10 & 19 \\
\hline Unsatisfactory & 1 & 0 & 1 & 0 & 0 & 1 & 0 & 0 \\
\hline$p$ & \multicolumn{2}{|c|}{$p=0.390^{*}$} & \multicolumn{2}{|c|}{$p=0.371^{*}$} & \multicolumn{2}{|c|}{$p=1.000^{*}$} & \multicolumn{2}{|c|}{$p=1.000^{*}$} \\
\hline \multicolumn{9}{|c|}{ Marginal discoloration } \\
\hline Satisfactory & 15 & 25 & 13 & 22 & 12 & 20 & 11 & 19 \\
\hline Unsatisfactory & 0 & 0 & 0 & 0 & 0 & 1 & 0 & 0 \\
\hline$p$ & \multicolumn{2}{|c|}{$p=1.000^{*}$} & \multicolumn{2}{|c|}{$p=1.000^{*}$} & \multicolumn{2}{|c|}{$p=1.000^{*}$} & \multicolumn{2}{|c|}{$p=1.000^{*}$} \\
\hline \multicolumn{9}{|l|}{ Retention } \\
\hline Satisfactory & 13 & 22 & 12 & 21 & 11 & 19 & 10 & 18 \\
\hline Unsatisfactory & 3 & 3 & 1 & 1 & 2 & 2 & 1 & 1 \\
\hline$p$ & \multicolumn{2}{|c|}{$p=0.662^{*}$} & \multicolumn{2}{|c|}{$p=1.000^{*}$} & \multicolumn{2}{|c|}{$p=0.627^{*}$} & \multicolumn{2}{|c|}{$p=1.000^{*}$} \\
\hline \multicolumn{9}{|l|}{ Secondary caries } \\
\hline Satisfactory & 16 & 25 & 13 & 22 & 13 & 19 & 11 & 19 \\
\hline Unsatisfactory & 0 & 0 & 0 & 0 & 0 & 2 & 0 & 0 \\
\hline$p$ & \multicolumn{2}{|c|}{$p=1.000^{*}$} & & & & & & \\
\hline
\end{tabular}

*Fisher's exact test. 
In the present study, in addition to finding no significant difference in the frequency of failures between the groups, no difference was found in the scores. Considering the clinical aspects of the USPHS-Modified criteria, the failures in the HG group were frequently associated with retention, secondary caries, marginal adaptation and discoloration, suggesting more difficult adhesion in hypomineralized enamel.

Sealant retention in hypomineralized enamel was also retrospectively evaluated by Lygidakis et al., ${ }^{18}$ who reported a retention rate of $79 \%$ at 12 months and $47 \%$ at 24 months. However, this previous study did not make comparisons with a control group that was unaffected by MIH. Although the difference was not statistically significant, the present study observed a retention rate of $72 \%$ in the HG group, and $62 \%$ in the CG group after 18 months, suggesting that the use of sealants for FPMs affected by MIH may be a valid preventive measure.

Previous in vitro studies found that hypomineralized enamel presented significantly lower microshear bond strength, compared with sound enamel. ${ }^{30,31}$ The enamel-resin adhesive interface has been found to be weaker in MIH-affected FPMs, compared with sound enamel, possibly because of limited interprismatic enamel dissolution, higher porosity, greater organic content and lower microtag formation in affected enamel. ${ }^{29,31,32}$ One possible explanation for our findings may be that sealant adherence occurred on the surface of the enamel, which may have been remineralized by prior preventive treatments with fluoride varnish. Bullio Fragelli et al. ${ }^{6}$ found that preventive treatment with a fluoride varnish favored remineralization and decreased the risk of fractures and carious lesions in MIH-affected FPMs. Furthermore, opacities with yellow-brown coloration are more porous and located

\section{References}

1. Jeremias F, Koruyucu M, Küchler EC, Bayram M, Tuna EB, Deeley K et al. Genes expressed in dental enamel development are associated with molar-incisor hypomineralization. Arch Oral Biol. 2013;58(10):1434-42. https://doi.org/10.1016/j.archoralbio.2013.05.005 throughout the thickness of the enamel, whereas white/yellow defects are less porous. ${ }^{33}$ Adhesion of the sealant would be unfavorable in more porous teeth.

The participants in the present study were entered into a preventive program that began with eruption of their FPMs, in an effort to maintain the integrity of the affected enamel. ${ }^{23}$ This was possible only because of early diagnosis of MIH. If the diagnosis is performed following post-eruptive fractures, the treatment of these cases may be more difficult, because of the lower adhesion of restorative materials to teeth with hypoplasia and post-eruptive fractures. ${ }^{17}$ An effort should be made to detect this condition as soon as eruption of the FPMs begins.

One limitation of the present study was the relatively small sample size. A larger sample may give the results more statistical power to reveal possible differences between groups. Future studies should also include a longer follow-up time.

\section{Conclusion}

In conclusion, the 18-month follow-up indicated that the survival of sealants in FPMs affected by $\mathrm{MIH}$ is not significantly different from that of FPMs unaffected by MIH, suggesting that applying the sealant may be an effective approach to preventing carious lesions in MIH-affected FPMs. Further research should be performed on sealant application for MIH-affected FPMs, at different stages of eruption, and on the use of different sealant materials. ${ }^{6}$

\section{Acknowledgments}

This study was supported by the Brazilian Coordination of Superior Education, Ministry of Education (Capes) and Fapesp (2011/17528-2). 
3. Vieira AR, Kup E. On the etiology of molar-incisor hypomineralization. Caries Res. 2016;50(2):166-9. https://doi.org/10.1159/000445128

4. Fagrell TG, Dietz W, Jälevik B, Norén JG. Chemical, mechanical and morphological properties of hypomineralized enamel of permanent first molars. Acta Odontol Scand. 2010;68(4):215-22. https://doi.org/10.3109/00016351003752395

5. Weerheijm KL. Molar incisor hypomineralisation (MIH). Eur J Paediatr Dent. 2003;4(3):114-20.

6. Bullio Fragelli CM, Jeremias F, Souza JF, Paschoal MA, Cordeiro RCL, Santos-Pinto L. Longitudinal evaluation of the structural integrity of teeth affected by molar incisor hypomineralisation. Caries Res. 2015;49(4):378-83. https://doi.org/10.1159/000380858

7. Lygidakis NA, Wong F, Jälevik B, Vierrou AM, Alaluusua S, Espelid I. Best clinical practice guidance for clinicians dealing with children presenting with MolarIncisor-Hy pomineralisation (MIH): an EAPD policy document. Eur Arch Paediatr Dent. 2010;11(2):75-81. https://doi.org/10.1007/BF03262716

8. Grošelj M, Jan J. Molar incisor hypomineralisation and dental caries among children in Slovenia. Eur J Paediatr Dent. 2013;14(3):241-5.

9. Jeremias F, Souza JF, Silva CMC, Cordeiro RC, Zuanon AC, Santos-Pinto L. Dental caries experience and molar-incisor hypomineralization. Acta Odontol Scand. 2013;71(3-4):870-6. https://doi.org/10.3109/00016357.2012.734412

10. Opydo-Szymaczek J, Gerreth K. Developmental enamel defects of the permanent first molars and incisors and their association with dental caries in the region of Wielkopolska, Western Poland. Oral Health Prev Dent. 2015;13(5):461-9. https://doi.org/10.3290/j.ohpd.a33088

11. Pitiphat W, Savisit R, Chansamak N, Subarnbhesaj A. Molar incisor hypomineralization and dental caries in six- to sevenyear-old Thai children. Pediatr Dent. 2014;36(7):478-82.

12. Jälevik B, Klingberg GA. Dental treatment, dental fear and behaviour management problems in children with severe enamel hypomineralization of their permanent first molars. Int J Paediatr Dent. 2002;12(1):24-32. https://doi.org/10.1046/j.0960-7439.2001.00318.x

13. Heitmüller D, Thiering E, Hoffmann U, Heinrich J, Manton D, Kühnisch J et al. Is there a positive relationship between molar incisor hypomineralisations and the presence of dental caries? Int J Paediatr Dent. 2013;23(2):116-24. https://doi.org/10.1111/j.1365-263X.2012.01233.x

14. Lygidakis NA. Treatment modalities in children with teeth affected by molar-incisor enamel hypomineralisation (MIH): a systematic review. Eur Arch Paediatr Dent. 2010;11(2):65-74. https://doi.org/10.1007/BF03262715

15. Fayle SA. Molar incisor hypomineralisation: restorative management. Eur J Paediatr Dent. 2003;4(3):121-6.
16. Mathu-Muju K, Wright JT. Diagnosis and treatment of molar incisor hypomineralization. Compend Contin Educ Dent. 2006;27(11):604-10.

17. William V, Messer LB, Burrow MF. Molar incisor hypomineralization: review and recommendations for clinical management. Pediatric Dent. 2006;28(3):224-32.

18. Lygidakis NA, Dimou G, Stamataki E. Retention of fissure sealants using two different methods of application in teeth with hypomineralised molars (MIH): a 4 year clinical study. Eur Arch Paediatr Dent. 2009;10(4):223-6. https://doi.org/10.1007/BF03262686

19. Jälevik B. Prevalence and diagnosis of MolarIncisor- Hypomineralisation (MIH): a systematic review. Eur Arch Paediatr Dent. 2010;11(2):59-64. https://doi.org/10.1007/BF03262714

20. Weerheijm KL, Duggal M, Mejàre I, Papagiannoulis L, Koch G, Martens LC, et al. Judgement criteria for molar incisor hypomineralisation (MIH) in epidemiologic studies: a summary of the European meeting on MIH held in Athens, 2003. Eur J Paediatr Dent. 2003;4(3):110-3.

21. Chow S, Shao J, Wang H, editors. Sample size calculations in clinical research. 2nd ed. Boca Raton: Chapman \& Hall; 2008.

22. Cvar JF, Ryge G. Reprint of criteria for the clinical evaluation of dental restorative materials. Clin Oral Investig. 2005;9(4):215-32. https://doi.org/10.1007/s00784-005-0018-Z

23. Vann WF, Jr., Divaris K, Gizlice Z, Baker AD, Lee JY. Caregivers' health literacy and their young children's oral-health-related expenditures. J Dent Res. 2013;92(7 Suppl):55S-62S. https://doi.org/10.1177/0022034513484335

24. World Health Organization. Oral health surveys: basic methods. Geneva: World Health Organization; 1997.

25. Arnold CL, Davis TC, Berkel HJ, Jackson RH, Nandy I, London S. Smoking status, reading level, and knowledge of tobacco effects among low-income pregnant women. Prev Med. 2001;32(4):313-20. https://doi.org/10.1006/pmed.2000.0815

26. Mahoney E, Ismail FS, Kilpatrick N, Swain M. Mechanical properties across hypomineralized/hypoplastic enamel of first permanent molar teeth. Eur J Oral Sci. 2004;112(6):497-502. https://doi.org/10.1111/j.1600-0722.2004.00162.x

27. Leppäniemi A, Lukinmaa PL, Alaluusua S. Nonfluoride hypomineralizations in the permanent first molars and their impact on the treatment need. Caries Res. 2001;35(1):36-40.

28. Bravo M, Montero J, Bravo JJ, Baca P, Llodra JC. Sealant and fluoride varnish in caries: a randomized trial. J Dent Res. 2005;84(12):1138-43. https://doi.org/10.1177/154405910508401209

29. William V, Burrow MF, Palamara JE, Messer LB. Microshear bond strength of resin composite to teeth affected by molar hypomineralization using 2 adhesive systems. Pediatric dentistry. 2006;28(3):233-41. 
30. Mahoney EK, Rohanizadeh R, Ismail FS, Kilpatrick NM, Swain MV. Mechanical properties and microstructure of hypomineralised enamel of permanent teeth. Biomaterials. 2004;25(20):5091-100. https://doi.org/10.1016/j.biomaterials.2004.02.044

31. Xie Z, Kilpatrick NM, Swain MV, Munroe PR, Hoffman M. Transmission electron microscope characterisation of molar-incisor-hypomineralisation. J Mater Sci Mater Med. 2008;19(10):3187-92. https://doi.org/10.1007/s10856-008-3441-2
32. Jälevik B, Dietz W, Norén JG. Scanning electron micrograph analysis of hypomineralized enamel in permanent first molars. Int J Paediatr Dent. 2005;15(4):233-40. https://doi.org/10.1111/j.1365-263X.2005.00644.x

33. Jälevik B, Odelius H, Dietz W, Norén JG. Secondary ion mass spectrometry and X-ray microanalysis of hypomineralized enamel in human permanent first molars. Arch Oral Biol. 2001;46(3):239-47. https://doi.org/10.1016/S0003-9969(00)00113-8 